\title{
Copyright issues related to the digitization of cultural heritage in Croatia
}

\author{
Aleksandra Horvat, Ph.D., Prof. \\ Faculty of Humanities and Social Sciences \\ University of Zagreb \\ Ivana Lucica 3, Zagreb, Croatia \\ Email: ahorvat@ffzg.hr \\ Daniela Zivkovic, Ph.D., Assoc. Prof. \\ Faculty of Humanities and Social Sciences \\ University of Zagreb \\ Ivana Lucica 3, Zagreb, Croatia \\ Email: dzivkovi@ffzg.hr
}

\begin{abstract}
A proliferation of the EU programmes and action plans on digitization proves that there is a political will to digitize and make available to the public the rich cultural heritage of Europe. The article tracks the development of these ideas and actions and focuses on one of the obstacles to overcome - the lack of consistency in approaches to intellectual property rights. The aim of the investigation described in the paper has been to find out how copyright issues related to the digitization performed by public institutions such as libraries and archives have been dealt with in Croatia. Information collected from the national electronic portal Croatian Cultural Heritage was further enriched by interviews held with the persons responsible for digitization projects in four major public institutions in the country. A lack of suitable registries or databases with data on the national authors has been noted. Institutions show different approach to digital copies they produce; some consider themselves to be publishers and rights holders of new digital editions of works, while the others take digitization primarily as a means of protection of originals. As a rule institution have a policy of copyright management, even if a rudimentary one. All institutions provide copyright information, sometimes with a copyright disclaimer. They use watermarking as a technical protection measure. Digitized materials are provided at no cost on the Internet for private use and research. Use of materials for commercial purposes has to be paid for and the institutions look upon it as a source of revenue to fund further digitization activities. The institutions' policy toward derivative works, i.e. offering the opportunity to users to create their own content is yet to be determined.
\end{abstract}

Keywords: digitization, copyright, orphan works, user created content, cultural heritage, Croatia, EU digitization policy.

\section{Introduction}

The fact that mass digitization is today not only technically feasible but has become a political and social issue of great importance has certainly contributed to the resurgence of discussions about copyright. In the last decade the European Union has adopted a number of official documents in the form of reports, recommendations and resolutions, etc. on digitization. The European Commission first called for measures to stimulate the development and use of digital content in the eEurope 2002 Action Plan. The eEurope Action Plan was endorsed by EU Member States in June 2000, encouraging the Commission and the Member States to "create a coordination mechanism for digitization programs across member States".

As a first step towards EU-wide coordination of digitization programs and policies, the European Commission organized an expert meeting with representatives from all member states in Lund in April 2001. The conclusions and recommendations derived from this meeting are known as the Lund principles. Among various obstacles they recognize intellectual property rights and state that various stakeholders in the digitized content have different legitimate interests which should be balanced. Solutions for handling and managing rights need to be understood and applied by the cultural sector if the economic value of the content is to be realized in a sustainable way. They "established priorities to add value to digitization activities in ways that would be sustainable over time". Lund Action Plan recommended actions for the period until 2005. The Lund Action Plan was implemented by a group of national representatives. The Group, appointed by the national Authorities for Culture in the EU, met in Parma in 2003 and agreed on a set of principles enumerated in the Charter of Parma. The Art. 4 of the Charter recognizes not only intellectual property rights, but also privacy of the individuals as obstacles and encourages the adoption of all the 
available technical and legal instruments to improve accessibility and overcome legislative and normative barriers. It also encourages a dialogue between the cultural and scientific sectors, intellectual property experts, companies implementing Digital Rights Management solutions and the content industries.

In 2005 the successor of the Lund Action Plan was presented under the title Dynamic Action Plan for the EU coordination of digitization of cultural and scientific content. It builds upon the previous. Let us mention just two of the six objectives like strengthening co-ordination and forging stronger links between Member States digitization initiatives, EU networks and projects and improving online access to European cultural heritage.

The proliferation of official documents concerning digitization in the EU shows clearly that digitization of various kinds of materials including books, newspapers, films, photographs, and maps held in libraries, archives and other public institutions throughout Europe has been strongly encouraged and supported not only as a means of preservation of the vast European cultural heritage and the instrument by which the heritage can be made available to a wider audience than ever before, but also as an incentive to the further development of the creative industry and the content market.

Analyzing the results of those efforts at the European level the following obstacles to mass digitization have been observed: cost, use of inappropriate technologies and inadequate standards, lack of synergy between cultural and technological programmes and the lack of consistency in approaches to intellectual property rights. (Cultural heritage, 2007; the authors' italics)

\section{Copyright as an obstacle}

The basic principle of the EU Directive on the harmonisation of certain aspects of copyright and related rights in the Information society from 2001 was to provide rights holders with a high level of protection by adapting the exclusive rights to the online environment. It also introduced an exhaustive list of exceptions to copyright protection. This list does not allow EU states to maintain or introduce exceptions which are not listed. The three-step test from the Berne Convention for the Protection of Literary and Artistic Works has become a benchmark for all copyright limitations. In 2008 the EC Commission issued a Green paper Copyright in the Knowledge Economy with the aim to improve the free movement of information and initiate a debate on the dissemination of creative works in the digital environment, not being limited to scientific and educational. Its aiming at all materials which have value in enhancing knowledge is of great importance to digitization projects of cultural heritage. The issues connected to copyright, such as present exceptions and limitations to copyright protection of use to libraries and archives, exceptions for handicapped persons and use of works in education were raised. The possible directions of further development with regard to exceptions were outlined: contractual arrangements between rights holders and users for the implementation of existing copyright exceptions and contractual arrangements between rights holders and users on other aspects not covered by copyright exceptions. One of the solutions would be that certain categories of exceptions might be made mandatory to ensure more legal certainty and better protection of beneficiaries of exceptions. The Green Paper focuses on the exceptions to copyright which are most relevant for the dissemination of knowledge. In the first place exceptions for libraries and archives are mentioned. Under the current legal framework, libraries and archives do not enjoy a blanket exception from the right of reproduction. Reproductions are only allowed in specific cases such as preservation of works contained in the library holdings (Directive, 2001, Art. 5(2)) and that covers preservation function of digitization. But libraries are interested in making these digital copies accessible online. Unfortunately, publicly accessible libraries, educational establishments, museums and archives do not benefit from the exception to the communication to the public right and the making available right for the purpose of research or private study by means of dedicated terminals located on the premises of such establishments (Directive, 2001, Art. 5(3)(n)) when making digitized works available online. Other issues connected to copyright, such as present exceptions and limitations to copyright protection of use to libraries and archives, exceptions for handicapped persons and use of works in education were raised and the problems related to orphan works were enumerated.

International organizations, such as IFLA and eIFL which support libraries, have quickly realized the possible obstacles to libraries wishing to digitize their material. As early as in 2002 IFLA had published its Guidelines for digitization projects for collections and holdings in the public domain, particularly those held by libraries and archives. IFLA suggests criteria for selection, technical requirements and implementation, legal aspects, budgeting, development and maintenance of web interfaces, preservation of digital content and project management. The Guidelines identify and discuss the key issues involved in conceptualization, planning and implementation with recommendations for best practices to be followed. They are aimed at decision makers, library and archive managers particularly in developing countries and are a part of the UNESCO strategy of knowledge for all. 
One chapter of the Guidelines addresses legal aspects of digitization. Institutions planning a digitization project must investigate the copyright situation for each item, take steps to prevent unauthorized changes in the digital files created during the project, ensure that the project complies with appropriate local legal deposit legislation and put in place a clear policy on access to and use of images within the completed digital project, including, if necessary, provision of copyright disclaimer forms. A recommendation is made to the institutions that the first issue to address in a digitization project or programme is the legal conditions for making digital copies.

Association of European Research Libraries (LIBER) has recently formulated its view of copyright in the digital environment stating strongly that access to and sharing of information and not copyright is the basis for scholarly activity supporting the idea that equitable access to information is vital for social, educational, cultural, democratic and economic well-being of people in Europe. The specific situation with copyright in Europe is that legislation exists at both European and national levels. LIBER advocates a stronger and unified European copyright regime, which balances the rights of rights holders and those of users. In order to ensure access to a broad range of information resources publicly-financed digital content should remain in the public domain. Though public private partnerships have an important role in helping achieve the European Commission's strategy for digitization, public private partnerships contracted in order to digitize content should be licensed for maximally 10 years. Yet, charges for the delivery of high quality images, sound and video recordings and print-on-demand materials are allowed. The future European copyright rules should stimulate the use and re-use of content as well as development of new models of fair remuneration for the rights holders. Contractual overriding of copyright law and its exceptions should be prevented.

In the beginning of this decade a pressure seems to have been put to WIPO, as the UN organization in charge of copyright issues at the international level, to change the present copyright policy at least when exceptions and limitations to copyright are concerned (EIFL, IFLA and LCA Statement of principles, 2009). Experts gathered at recent sessions of the WIPO SCCR, together with representatives from library and information associations, such as IFLA/CLM, eIFL, etc. have tried to analyze and explore the existing limitations and exceptions including those which are considered to be of use to libraries and archives (WIPO SCCR, 2009, 19/3). The overall opinion seems to prevail that present copyright laws in the European countries have not been amended to enable libraries and archives to operate efficiently and adequately in the global digital environment. It seems also that present copyright exceptions and limitations are increasingly undermined by licensing practices which sometimes overrule the national copyright laws.

\section{Copyright clearance}

Digitization is an act of both reproduction and communication to the public and therefore requires a permission of the author/rights owner or her/his representative, if the work is copyrighted. A public institution engaged in digitization first has to identify the author and determine if the work is still protected (in the EU the work is protected during an author's lifetime and the 70 years following his/her death). Also, the copyright for a protected work could have been transferred to another physical or legal person. Tracing the rights holders could be a lengthy and burdensome process, even more so if a library wishes to digitize various kinds of materials, such as phonograms, artefacts, letters, etc. Libraries are also interested in the material created by the local people or amateurs. In a more than a decade old paper on copyright clearance and digitization in higher education Bide, Oppenheim and Ramsden (1997) discuss the need for "one-stop shop" for the clearance of digitization rights. The authors believe that a central agency for rights clearance is highly desirable, although they find a possible disadvantage of "one-stop shop" method of paying for the rights in the impossibility of negotiability of rates. A contract or a license should be as brief and straightforward as possible and unambiguous in the wording. Unfortunately thirteen years after the one-stop shop for the clearance of rights is still to be wished for.

\section{Orphan works}

The main problems with the present copyright regime seem to originate in the inability of the institutions such as libraries and archives, to trace and locate rights holders in many cases. The continental law system, as distinct from the Anglo-American, has never required the registration of copyright, and now when libraries wish to find authors and other rights holders, they are quite often at a loss. There is no agency which could provide data on authors and other rights holders not only at a global level, but often within a country. It is a true paradox that libraries which have 
acquired such rich expertise in organizing catalogues and bibliographies and determining various kinds of authorship have now been confronted with a lack of adequate data on authors.

In Europe, but also in the US and Canada, a lot of work has been put into trying to solve the so-called orphan works problems but adequate solutions are still searched for. Libraries and archives hesitate to select orphan works for digitization since their copyright status is difficult to determine. Ephemeral materials such as photographs, postcards, posters, programmes of local events, etc. belong to that category of works and that kind of content seems to be particularly interesting for the institutions that keep them because of its historical or cultural value for the community in which the material had been created. They witness the historical development of a town, village, region and are interesting for researchers of local history, historians, teachers and the public at large. Unfortunately libraries and archives keep little or no information on the creators of such material. According to some estimates several millions of items belong to the category of orphan works (In from the cold, 2009). According to the British Library around $40 \%$ of all creative works are orphan works (In from the cold, 2009). Research done in the UK has shown that 5-10\% of each public institution collections would probably never be digitized because the rights cannot be cleared. Naturally, it is the 20th century works that are at risk of not being digitized and available to the public. In the i2010 Digital Libraries the experts state that clarification and transparency in the copyright status of a work is an essential element in a number of areas, including the European Digital Initiative (EDI). The EDI was launched by the European Commission in 2005 to provide a common multilingual access point to Europe's digital cultural heritage as a part of the i2010 strategy. In its 2006 recommendation the Commission recommended the creation of mechanisms to facilitate the use of orphan works. Within the EDI efforts were made to give guidance to national measures to implement the recommendation. In 2007 a decision was made to develop sector-specific guidelines on due diligence criteria for orphan works. It was concluded that in addition to guidelines databases which contain information on orphan works would be beneficial. First step in this respect was made by the ARROW (Accessible Registries of Rights information and Orphan Works) project which gathers national libraries, collective management organizations and publishers and is co-funded by the European Commission under the eContent plus programme with $€ 2.5$ million. This project was launched in November 2008 to link different European rights registries as a first attempt.

One of the early statements on orphan works was made by the Libraries and Archives Copyright Alliance (LACA) in 2007. It gives a precise definition of the orphan work, explains the nature of the problem and offers several applicable solutions: licensing, diligent search, and mass digitization solution. The last one would allow not-for-profit educational, cultural and research institutions working with large numbers of orphan works to use them under a new exception. Issues to consider with these solutions are discussed as a kind of practical guidance.

In October 2009 the European Commission adopted a Communication on Copyright in the Knowledge Economy aiming to tackle the important legal aspects of mass-scale digitization and dissemination of European libraries. The experiences gained with the Digital Library Europeana and consultations on the Green Paper contributed that European Commission puts challenges of books digitization for authors, libraries and consumers on the EU agenda (Communication from the Commission, 2009).

\section{User created content}

The Green Paper Copyright in the Knowledge Economy has also opened up a debate on knowledge dissemination in the online environment focusing on the relevant exceptions to copyright, which should include a possible exception for user-created content. Digital portals, considered to be particularly efficient places of knowledge dissemination, are expected to contain user created content such as blogs, podcasts, wiki or video sharing, enabling users to easily create and share text, videos and pictures. Registered Europeana users, for instance, can save a search, add a tag, save an item or share it with a friend. Since the Directive (2001) does not contain an exception which would allow the use of existing copyright protected content for creating new or derivative works, the obligation to clear rights before any transformative user created content is made available is seen as an obstacle to the free dissemination of knowledge at present.

\section{Digitization of cultural heritage in Croatia}

Sporadic digitization of some valuable items or items of special interest in public institutions such as libraries, archives and museums took place as early as the late nineties of the $20^{\text {th }}$ century. In 2006 an encompassing national programme of digitization of the cultural heritage kept in libraries, archives and museums throughout the country was 
initiated by the Ministry of Culture. The first step was to gather all collections already digitized by cultural institutions in the country and display them on an electronic portal, allowing new collections to be added along. The portal Croatian Cultural Heritage was developed as a central networking point that would enable accessibility and browsing of digital collections and as an efficacious means of coordination, i.e. the visibility of projects on the portal decreased the possible duplication of the material in the collections. In line with international documents standards and guidelines for the digitization of material have been elaborated and institutional capacities for digitization strengthened. The portal has succeeded in gathering around 60 cultural and educational public institutions as participants. Since 2007 the number of collections displayed at the portal (http://www.kultura.hr) has been on the constant increase. The Ministry takes care of the portal and if needed offers technical support and advice. It also acts as a coordinator of the whole project. The institutions involved in the project have the freedom to select the material, prepare it for digitization, i.e. check completeness, do repairs if needed, add metadata, provide names of datafiles, etc. Technical part of the process is done either by professional firms or by departments of the institutions themselves, in case they have at their disposal the adequate equipment. In 2010 a total of 34 digitization programs proposed by various public institutions have been approved and financed by the Ministry of Culture (a total of $€ 720,000)$.

\section{The investigation}

The aim of the investigation has been to find out how copyright issues related to the digitization performed by public institutions, such as libraries and archives have been dealt with in Croatia. This seemed to be interesting because little about that specific topic could be found on the portal itself and/or the cultural institutions' websites. Also, the national Copyright Act (2003) modelled in accordance with the EU Directive from 2001 does not explicitly mention digitization and is very cautious in providing exceptions to copyright protection. We were also aware that librarians and archivists in charge of digitization would have very little prior experience with copyright and we were curious to learn about their approach to the process of clearing rights.

The national portal Croatian cultural heritage was naturally our first source of information on how copyright is dealt with. But the portal simply claims that the rights on all the contents displayed belong to the Ministry of Culture. Moreover, in the same statement the Ministry waves away any responsibility for the incorrectness or incompleteness of data. We found the statement to be somewhat ambiguous and made a decision to interview persons responsible for digitization projects in four largest institutions participating in the project, hoping that they might provide us with more inside knowledge. The institutions were: the National and University Library in Zagreb, the central library in the country, Zagreb City Libraries, the most important public libraries network in the country, the Croatian State Archives, and the Croatian Academy of Sciences and Arts. The fact that all institutions selected for the interviews are located in the capital might perhaps seem constraining, but at present they seem to be the leaders in digitization projects in the country. The interviews with persons responsible for digitization projects in those institutions were recorded on tape. The direct communication with colleagues helped us indeed to obtain the answers that could not have been obtained from the portal and to get a better insight into the copyright situation. Thus the interview was not used as a method to obtain personal opinions, but as a means to clarify the ambiguous issues to which there was no explicit answer in other sources.

A number of digitization projects carried out by libraries, archives and museums in Croatia and displayed on the Croatian Cultural Heritage portal prove that Croatian librarians, archivists and museum curators follow the trends in other European countries trying to preserve and make available to the larger public the cultural heritage in their custody. However, considering the current hesitation of the EU public institutions to digitize the 20th century material because of the expected obstacles in identifying and locating rights holders (see for instance the LIBER Response to the EC Creative Content Online Consultation, from December 2009, where the 20th century is described as the black hole), one would expect that the digitized 20th century material is scarce in Croatia, too. But even a short glance at the portal shows clearly that the majority of collections digitized (136) have been classified as containing the 20th century materials. However, a closer inspection will also prove that those collections contain material that span centuries and that only a part of the material in the collection belongs to the 20th century. Also, most of the 20th century collections seem to be collections of photographs, plans, posters and similar documents. But some collections house newspaper and journals clippings and some contemporary newspaper runs have also been digitized. It cannot be deduced from the portal itself how the rights have been cleared for every collection, apart from the already mentioned general copyright notice stating that the Ministry holds all rights for the materials displayed on the portal.

The colleagues in charge of digitization admit that the 20th century material has rarely been selected for digitization not only because of a fear that copyright clearance would require too much time and effort, but also because remuneration to rights holders would increase the envisaged expenses. Those answers led us to conclude that copyright remuneration was not foreseen as an expense in the project. The conclusion was corroborated by colleagues 
who confirmed that their institutions' project proposals did not contain any provision on copyright clearance expenses. However, in spite of the decision to evade the 20th century material, the Zagreb City Library came across a right that had to be cleared. The decision to digitize the first edition of a well-known classic children book of the author whose rights expired a few years ago, proved to be unwise, because the edition also contained illustrations made by a painter, who died 20 years ago and whose rights were still held by her niece. Although in the end the Library did not have to pay any royalties and the rights holder's only requirement was to obtain a digital copy, the length of the search for the right holder and the time and skill required to compose an agreement with her, proved to be a cumbersome task for the Library. Since there was no information on the illustrator in the library catalogue, the search began with the Museum where the painter's retrospective exhibition was last organized almost 15 years ago, and the Museum's curators were indeed able to identify the present rights holder, but the search and further negotiations with the rights holder took a whole month. Taking into account the fact that externally funded digitization projects are to be carried out according to a predetermined time schedule, such inadvertent prolongation can be a serious impediment.

The Croatian Academy of Sciences and Arts, which has been a major publisher of scientific and research works in the country for the last hundred years decided to digitize its own publishing output first. It opted for the open access, and the authors sign a contract and transfer their rights to the Academy. However, an option has been provided for the authors of older but still protected works to withhold the rights if they disagree with the policy of open access. Yet, this has not been the case, so far.

Interviews with colleagues revealed a sharp difference in the approach to digitization. For the librarians of the National and University Library digitization is primarily seen as a means of preservation, a new digital copy of a work is just another copy of the original held by the Library, although in a different format. In the words of the colleague the digital copy is made to preserve the original. On the contrary librarians in the Zagreb City Library strive to make an ideal copy; they try to 'embellish' the original not only by cleaning it from smudges, rust, etc., but also by removing all ex-libris, personal signatures and notes written on margins. If the Library copy is incomplete, they borrow a copy from another institution and amend their own copy. The Library's intention is to produce a new digital edition of the work. They also add a new imprint in the colophon of the digital copy and a new ISBN, and by doing that they openly claim that they are publishers of a new edition. Thus the City Library makes a new catalogue record, for a digital work, while the National and University Library just adds a note on the catalogue record of the original. Consequently, according to the Copyright Act the City Library could claim the rights on the new edition and perhaps even require remuneration for the use.

For the Croatian Academy of Sciences and Arts digitization is to a certain degree a means of preservation, but mostly it is an opportunity to make the works of its members accessible to a wider public. It allows the Academy to fulfil its main tasks: publish the results of scientific research and promote science.

In 2005 the National and University Library in Zagreb launched a website Digitized heritage making a selection from the older national material as a part of the Digitization project of the Library. Up to now more than 700 items have been digitized, mostly books, manuscripts and printed music, but also a collection of posters, drawings and maps as well as a few sound recordings. In spite of its initial decision to digitize only the material of national significance free of copyright, according to the librarian in charge of digitization, copyrighted material could not be completely evaded, and agreements have been concluded with artists (authors of posters) and performers of music on sound recordings. When permission is asked for, authors are approached individually, often by e-mail and the authorization is in fact an e-mail reply received from the author. There is no special agreement concluded with the authors. The right clearance for the sound recordings was obtained in writing by a collecting society responsible for music composers and performers.

A colleague librarian in charge of phonograms in the City Library discovered that she had to contact four different producers and the digitization of old gramophone records envisioned in 2008 had to be postponed to 2009.

The National and University Library also plans to digitize the 100 dissertations defended at the Zagreb University from the second half of the 19th century onwards. Some of those dissertations could still be protected, and the copyright holders should be found. Catalogue authority file which is normally consulted when basic data on authors are searched for is likely to be of no use in this case, because old catalogue records do not contain data on the authors' birth/death. However, the Lexicographic Institute in Zagreb, the publisher of numerous encyclopaedia and lexicons, holds a database of biographical data on persons who had been active in various segments of social life in Croatia, researchers and scientists included, and the Institute is willing to make its database available to the National and University Library. But the database may be of help only in part, because what librarians really need are data on the transfer of rights and names and addresses of right holders and there is no such database in the country. The Croatian Society of Composers runs an agency HDS/ZAMP, which is in fact a collecting society for music rights. But the data 
they hold are not available on the web and librarians have to put separate inquiries regarding an individual's rights to the HDS/ZAMP in writing.

The absence of any notice on orphan works or the possibility that an author whose work has been digitized comes forward after the digitization was done asserting his/her rights, has been conspicuous and proves that our librarians are still not fully aware of the full scope of copyright issues. Also, there is no information on the libraries' websites about possible false rights claims.

The City Library wanted to digitize a National Theatre Yearbook and Theatre Almanac and sent a request for permission to the National Theatre; they had to wait for an answer and succeeded in obtaining the permission after 7 months. This is interesting because it shows that the National Theatre as an important public institution has no plans to digitize its publications and/or archive for some time to come.

At its website the National and University Library has mounted a copyright notice stating that digital copies should not be published on the Internet or further distributed. They can be used for private purposes and research. Requests for commercial use should be sent in writing to the Library. Also, the users are obliged to cite the Library's portal as the source when using the material.

A great concern of colleagues in the National and University Library has been the fact that up to the present only material from special collections (maps, posters, music, old and rare books and manuscripts) has been selected for digitization. The general collection which includes the national collection Croatica, is digitized on demand only, meaning that if a user places an order for a digital copy of a work, the Library keeps a copy of its own. But this obviously means that the selection of the material to be digitized has been determined by the preferences of users.

The City Library provides a statement on the use of digital material. It allows the material to be used, but not for commercial purposes; downloaded material bears a watermark and can be used for reading but not for further reproducing.

Ambiguous copyright claims have also been noted. The National and University Library has paid royalties for digitization to the author of a catalogue of dissertations published by an institute almost forty years ago, although the catalogue had been composed as a part of the author's regular duties as an employee of the institute. This case could multiply in the future and employees of all kinds could claim rights for the works they created as part of their job obligations. In case of works on hire the current Copyright Act stipulates that work contract should contain a clause on who has the rights and in the second half of the 20th century such clauses were exceptions.

The Croatian State Archives seems to be more interested in the personal data protection than in copyright, although colleagues admit that they keep copyrighted material also. The Archive has very good equipment which allows for digitization of its own material as well as the material of other institutions. Up-to-now 1,600.000 pages of birth/death registries have been digitized and are available to the public. The Archives has not digitized sound or film materials, and textual material only appears on the portal Croatian Cultural Heritage. It is somewhat strange, since the Croatian Film Archive is a division of the State Archives. However, the Archives digitized the first Croatian film about a wellknown Croatian composer, but a copy can be obtained on DVD only. Since authenticity is crucial for the archival documents, the Archives issues a written confirmation of authenticity for a digital copy of a document, but the user has to demand it expressly.

When asked where and how they learned about copyright related to the digitization process, our colleagues replied that they attended the courses on digitization held in the Centre for Continuing Education of Librarians in Zagreb and used the copyright primer for librarians recently published in Zagreb (Horvat \& Zivkovic, 2009).

Although user created content (UCC) and its relation to copyright and/or licensing is an issue much discussed in literature at present (see for instance Helberger, N. et al.; Halbert, D.; Gervais, D.), we were not able to learn much about it in our investigation. Apart from the answers to frequently asked questions and e-mail contact availability the Croatian Cultural Heritage portal also provides an opportunity for the users to add their own content, but up-to-now nobody has used it. There is no blog and the site does not allow for users' feedback.

Recently however, the National and University Library has opened its Facebook page allowing both users and nonusers to learn about its activities and programmes and comment them. Users can send their proposals concerning content to be digitized to the Library. 


\section{Conclusion}

A proliferation of the EU programmes and action plans on digitization proves that there is a political will to digitize and make available to the public the rich cultural heritage of Europe. However, there are still obstacles to overcome, such as the high cost, lack of technical standards and lack of consistency in approaches to intellectual property rights. Since 2000 Croatian public institutions such as libraries, archives and museums have started digitizing their collections, but little can be learned from public sources about the solutions taken regarding rights clearing, an investigation has been carried out to find out more details and compare the situation with trends in the EU. The interviews held with persons responsible for digitization projects in four major public institutions in Croatia proved that Croatian librarians and archivists are aware of the fact that digitization is closely connected to copyright issues and that rights have to be cleared. They are also aware that they must investigate the copyright situation and legal position affecting access by users to the material created by the project. They have been able to gain a basic knowledge of copyright issues related to digitization by attending the courses in the Centre for Continuous Education of Librarians and by using a recently published book on copyright for librarians written in Croatian. Library catalogues serve as the first source of information on authors, but they are helpful only in determining if a work is still protected and lack all other information needed to trace and locate authors. A lack of suitable registries or databases with data on authors in the country is a further serious obstacle, and the only exception is a database on composers and performers kept by a collecting society for music rights. Institutions show different approach to their own role; the Croatian Academy of Sciences and Arts and Zagreb City Libraries consider themselves to be publishers and rights holders of new digital editions of works, while the National and University Library and the State Archive take digitization primarily as a means of protection of original works.

As a rule institutions have a policy of copyright management, even if a rudimentary one. All institutions provide copyright information, sometimes with a copyright disclaimer. They use watermarking as a technical protection measure. Digitized materials are provided at no cost on the Internet for private use and research. Use of materials for commercial purposes has to be paid and the institutions look upon it as a source of revenue to fund further digitization activities. A definitely distinct policy has been adopted by the Academy of Sciences and Arts which publishes results of research of its own members and which has decided to join the open access initiative. The policy of all institutions toward derivative works, i.e. offering the opportunity to users to create their own content and add/mix their contributions with the content digitized by the institutions is yet to be determined.

\section{References}

Berne convention for the protection of literary and artistic works. WIPO. Retrieved January 12,2010 from http://www.wipo.int/treaties/en/ip/berne/.

Bide, M., Oppenheim, Ch. \& Ramsden, A. Some proposals regarding copyright clearance and digitisation in higher education (1997). Journal of Information Science 23, 6, 393-405.

Charter of Parma. (2003). Retrieved $\quad$ December $22, \quad 2009$ from http://www.minervaeurope.org/structure/nrg/documents/charterparma031119final.htm.

Commission Recommendation of 24 August 2006 on the digitisation and online accessibility of cultural material and digital preservation. Brussels : Commission of the European Communities, 2006. Retrieved November 20, 2009 from http://eurlex.europa.eu/LexUriServ/LexUriServ.do?uri=OJ:L:2006:236:0028:0030:EN:PDF.

Communication on copyright in the knowledge economy. Brussels : Commission of the European Communities, 2009. (COM(2009)532final). Retrieved January 5, 2010 from http://ec.europa.eu/internal_market/copyright/docs/copyrightinfso/20091019_532_en.pdf.

Copyright in the knowledge economy : green paper. Brussels : Commission of the European Communities, 2008. (COM (2008)466/3). Retrieved November 15, 2009 from http://ec.europa.eu/internal_market/copyright/docs/copyrightinfso/greenpaper_en.pdf.

Crnkovic, K., Juricic, V., Polak Bobic, K. Digitalna zbirka knjiznice Hrvatske akademije znanosti i umjetnosti (2010) (in print).

Croatian Cultural Heritage. Retrieved January 10, 2010 from http://www.kultura.hr.

Cultural heritage. Information Society Technologies. (2007). Retrieved January 10, 2009 from http://cordis.europa.eu/ist/digicult/eeurope.htm. 
Directive 2001/29/EC of the European Parliament and of the Council of May 222001 on the harmonisation of certain aspects of copyright and related rights in the information society. Retrieved January 4, 2010 from http://www.ivir.nl/legislation/eu/copyright-directive.doc.

Dynamic action plan for the EU co-ordination of digitization of cultural and scientific content. (2005). Retrieved December 20, 2009 from http://www.minervaeurope.org/publications/dap/dap.pdf.

e-Europe2002 action plan / prepared by the Council and European Commission for the Feira Council. (2000). Retrieved November 20, 2009 from http://ec.europa.eu/information_society/eeurope/2002/action_plan/pdf/actionplan_en.pdf.

EIFL, IFLA and LCA Statement of principles on copyright exceptions and limitations for libraries and archives. (2009). Retrieved January 4, $2010 \quad$ from $\quad$ http://www.eifl.net/cps/sections/docs/ip_docs/statementprinciples/downloadFile/attachedFile_f0/StatementofPrinciples_English.pdf?nocache=1261508729.81.

European Parliament Resolution of 27 September 2007 on i2010 : towards a European digital library. (2007). Retrieved November 15, 2009 from http://www.europarl.europa.eu.

Final report on digital preservation, orphan works, and out-of print works / contributing authors Marco Ricolfi et al. (i2010: Digital libraries 03/06/2008). $\quad$ Retrieved $\quad$ November $10, \quad 2009$ from http://ec.europa.eu/information_society/activities/digital_libraries/doc/hleg/reports/copyright/copyright_subgroup_final_report_ 26508-clean171.pdf.

Gervais, D. The tangled Web of UGC: making copyright sense of user-generated content (2009). Vanderbilt Journal of Entertainment \& Technology Law, 11, 4, 841-870.

Halbert, D. Mass culture and the culture of the masses: a manifesto for user-generated rights (2009). Vanderbilt Journal of Entertainment \& Technology Law 11, 921-961.

Helberger, N. et al. Legal aspects of UCC. Retrieved April 6, 2010 from http://www.ivir.nl/index.html.

Horvat, A., \& Zivkovic, D. (2009). Knjiznice i autorsko pravo (Libraries and copyright). Zagreb : Hrvatska sveucilisna naklada.

IFLA Guidelines for digitization projects for collections and holdings in the public domain, particularly those held by libraries and archives. (2002). Retrieved October 14, 2009 from http://www.ifla.org.

In from the cold: an assessment of the scope of 'orphan works' and its impact on the delivery of services to the public. (2009). Retrieved November 20, 2009 from http://www.jisc.ac.uk/contentalliance/.

LACA Statement on Orphan Works. (2007). Retrieved November 26, 2009 from http://www.cilip.org.uk/sitecollectiondocuments/PDFs/policyadvocacy/laca/LACAorphanworksstatementFINAL19dec07.pdf

LIBER Response to the EC Creative Content Online Consultation. (2009). Retrieved January 18, 2010 from http://www.libereurope.eu/files/LIBER-Response-Creative-Content-Online-Consultation.pdf.

Lund action plan. (2001). Retrieved December 15, 2009 from ftp://ftp.cordis.europa.eu/pub/ist/docs/digicult/lund_action_planen.pdf.

Lund principles : conclusion of experts meeting, Lund, Sweden, 4 April 2001. (2001). Retrieved April 20, 2010 from http://cordis.europa.eu/ist/digicult/lund-principles.htm.

National programme of digitisation of archival, library and museum holdings : summary. Zagreb : Ministry of Culture, 2007. Retrieved April 20, 2010 from http://www.kultura.hr/eng/Join-in/Download-documents/The-National-Programme-ofDigitisation-of-Archival-Library-and-Museum-Holdings

WIPO Standing Committee on Copyright and Related Rights, Nineteenth session, Geneva, December 14 to 18, 2009. Analytical document on limitations and exceptions. (2009). SCCR19/3. Retrieved October 20, 2009 from http://www.wipo.int/meetings/en/doc details.jsp?doc id=129524.

The final publication is available at https://link.springer.com/book/10.1007/978-3-642-16032-5\#page=173 